\title{
Isolation and Characterization of Isofraxidin 7-O-(6'-O-p-Coumaroyl)- $\beta$-glucopyranoside from Artemisia capillaris Thunberg: A Novel, Nontoxic Hyperpigmentation Agent That Is Effective In Vivo
}

\author{
Soon-Ho Yim, ${ }^{1}$ Nadia Tabassum, ${ }^{2}$ Woong-Hee Kim, ${ }^{2}$ Haaglim Cho, ${ }^{2}$ \\ Ji-Hyung Lee, ${ }^{2}$ Galzad J. Batkhuu, ${ }^{3}$ Hyun Jung Kim, ${ }^{4}$ Won Keun Oh, \\ Da-Woon Jung, ${ }^{2}$ and Darren R. Williams ${ }^{2}$ \\ ${ }^{1}$ Department of Pharmaceutical Engineering, Dongshin University, Jeonnam, Republic of Korea \\ ${ }^{2}$ New Drug Targets Laboratory, School of Life Sciences, Gwangju Institute of Science and Technology, \\ Gwangju 500-712, Republic of Korea \\ ${ }^{3}$ School of Engineering and Applied Sciences, National University of Mongolia, Ulaanbaatar, Mongolia \\ ${ }^{4}$ College of Pharmacy and Natural Medicine Research Institute, Mokpo National University, Jeonnam, Republic of Korea \\ ${ }^{5}$ College of Pharmacy, Seoul National University, Seoul, Republic of Korea
}

Correspondence should be addressed to Da-Woon Jung; jung@gist.ac.kr and Darren R. Williams; darren@gist.ac.kr

Received 17 March 2017; Accepted 26 April 2017; Published 24 May 2017

Academic Editor: Victor Kuete

Copyright (C) 2017 Soon-Ho Yim et al. This is an open access article distributed under the Creative Commons Attribution License, which permits unrestricted use, distribution, and reproduction in any medium, provided the original work is properly cited.

\begin{abstract}
Abnormalities in skin pigmentation can produce disorders such as albinism or melasma. There is a research need to discover novel compounds that safely and effectively regulate pigmentation. To identify novel modulators of pigmentation, we attempted to purify compounds from a bioactive fraction of the Korean medicinal plant Artemisia capillaris Thunberg. The novel compound isofraxidin 7-O-(6'-O-p-coumaroyl)- $\beta$-glucopyranoside (compound $\mathbf{1})$ was isolated and its pigmentation activity was characterized in mammalian melanocytes. Compound 1 stimulated melanin accumulation and increased tyrosinase activity, which regulates melanin synthesis. Moreover, compound $\mathbf{1}$ increased the expression of tyrosinase and the key melanogenesis regulator microphthalmia-associated transcription factor (MITF) in melanocytes. Compared to the parent compound, isofraxidin, compound $\mathbf{1}$ produced greater effects on these pigmentation parameters. To validate compound $\mathbf{1}$ as a novel hyperpigmentation agent in vivo, we utilized the zebrafish vertebrate model. Zebrafish treated with compound 1 showed higher melanogenesis and increased tyrosinase activity. Compound 1 treated embryos had no developmental defects and displayed normal cardiac function, indicating that this compound enhanced pigmentation without producing toxicity. In summary, our results describe the characterization of novel natural product compound $\mathbf{1}$ and its bioactivity as a pigmentation enhancer, demonstrating its potential as a therapeutic to treat hypopigmentation disorders.
\end{abstract}

\section{Introduction}

Human skin is exposed to numerous environmental stresses, such as mutagenic ultraviolet radiation. Mutations or dysregulation of the genes that regulate pigmentation can produce hypopigmentation disorders, such as albinism or vitiligo [1, 2]. Hypopigmented lesions may disfigure the skin, produce psychosocial problems, and increase the probability of developing skin cancer [3].
Small molecule compounds that increase melanin synthesis have the potential to treat hypopigmentation disorders [4]. Numerous pigmentation enhancing agents have been discovered, such as diacylglycerols, 3-isobutyl-1-methylxanthine (IBMX), and dimethylsulfoxide (DMSO). However, their side effects can be a major concern, including the propensity to induce tumors $[5,6]$. Therefore, there is a need to discover new compounds that increase skin pigmentation. 
In this study, we identified a new pigmentation-regulating compound in the plant Artemisia capillaris Thunberg (A. capillaris; Oriental wormwood). The Artemisia genus has been used as a herbal medicine for a range of disorders, including inflammation, microbial infections, cancer, and malaria [7]. Extracts derived from Artemisia capillaris Thunberg have been shown to produce a number of biological effects, such as antiplatelet aggregation activity, hepatocyte protection, anti-inflammatory activity, antioxidant activity, antitumor activity, and antiobesity action [8-12]. Using an active fraction from $A$. capillaris, we purified a novel enhancer of pigmentation: isofraxidin $7-O-\left(6^{\prime}-O-p-\right.$ coumaroyl)- $\beta$-glucopyranoside (compound 1; Figure 1(a)). Compound 1 was found to produce hyperpigmentation effects in vivo, suggesting that it can be developed as a pharmaceutical/cosmetic agent to treat skin disorders resulting from reduced pigmentation.

\section{Materials and Methods}

2.1. General Experimental Procedures. Optical rotation was measured with a JASCO DIP-1000 digital polarimeter. UV spectra were recorded with a JASCO V-530 UV/Vis spectrophotometer (Jasco Corp., Japan) and IR spectra were obtained using a JASCO FT/IR-300E spectrometer (Jasco Corp., Japan). ${ }^{1} \mathrm{H}$ and ${ }^{13} \mathrm{C}$ NMR spectra were recorded using a Varian VNMRS $600 \mathrm{MHz}$ NMR spectrometer (Varian, Inc., USA) for $1 \mathrm{D}$ and $2 \mathrm{D} \mathrm{NMR}$ experiments in $\mathrm{CD}_{3} \mathrm{OD}$ [tetramethylsilane (TMS) was used as the internal standard]. The chemical shifts $(\delta)$ were expressed as parts per million (ppm) and the coupling constants $(J)$ were expressed in $\mathrm{Hz}$. Mass spectra were measured on a JMS-700 (Jeol, Japan) and Varian 1200, Platform II (Varian, USA) spectrometers. High resolution mass (ESI-MS) and LCMS/MS spectra were measured with a Waters Synapt High Definition Mass Spectrometry/time-of-flight mass spectrometer, using the negative electrospray ion mode.

2.2. Plant Materials. The active fraction (ACMF09) from Artemisia capillaris Thunberg was provided by Professor Soon-Ho Yim, Dongshin University, Jeonnam, Republic of Korea.

2.3. Reagents. IBMX, forskolin, phenylthiourea (PTU), sodium hydroxide $(\mathrm{NaOH})$, DMSO, L-3,4-dihydroxyphenylalanine (L-DOPA), caffeine powder, staurosporine, 3(4,5-dimethylthiazol-2-yl)-2,5-diphenyltetrazolium bromide (MTT), and CellLytic ${ }^{\mathrm{TM}}$ lysis buffer were purchased from Sigma (St Louis, MO, USA). Isofraxidin was purchased from ChemFaces Biochemical (Hubei, China).

2.4. Cell Culture. Murine melanoma B16F10 melanocytes were supplied by the American Type Culture Collection (ATCC, Manassas, VA) and cultured in DMEM containing $10 \%$ FBS and $1 \%$ penicillin-streptomycin mixture (Gibco, USA). Cells were cultured in a $37^{\circ} \mathrm{C}$ humidified incubator with $5 \% \mathrm{CO}_{2}$.
2.5. Determination of Melanin Content in B16F10 Melanocytes. The melanocytes were seeded in a 6 -well plate at a density of $2 \times 10^{5}$ cells/well. $24 \mathrm{~h}$ later, the cells were treated with compound of interest for $48 \mathrm{~h}$. Cells were washed with PBS and lysed with $4^{\circ} \mathrm{C}$ CellLytic buffer, followed by centrifugation at $13000 \mathrm{rpm}$ for $10 \mathrm{~min}$ at $4^{\circ} \mathrm{C}$. The pellet was used for melanin content analysis by two washes with ethanol: ether ( $1: 1$ volume) and dissolving in $200 \mu \mathrm{L} 1 \mathrm{~N} \mathrm{NaOH}$ containing $10 \% \mathrm{DMSO}$, with heating at $80^{\circ} \mathrm{C}$ for $1 \mathrm{~h} .100 \mu \mathrm{L}$ aliquots of the solution were measured for melanin content by reading the absorbance at $400 \mathrm{~nm}$ using a microplate reader $\left(\operatorname{VersaMax}^{\mathrm{TM}}\right.$; Molecular Devices Corporation, California, USA), as previously described.

2.6. Measurement of Melanin Secreted into the Culture Media. Based on the previously published protocol [15]. B16F10 melanocytes were seeded in a 24 -well plate at a density of $5 \times 10^{4}$ cells/well using $500 \mu \mathrm{L}$ culture media. $24 \mathrm{~h}$ later, the culture media were replenished and cells were treated with the compound of interest for $60 \mathrm{~h}$. The culture media were collected and melanin levels were measured at an absorbance wavelength of $475 \mathrm{~nm}$ using a microplate reader (VersaMax; Molecular Devices Corporation, California, USA).

2.7. Determination of Tyrosinase Activity in Melanocytes. Tyrosinase activity in the compound treated melanocytes was measured as previously described [16]. In brief, B16F10 melanocytes were seeded in a 6 -well plate at $2 \times 10^{5}$ cells/well. $24 \mathrm{~h}$ later, the cells were treated with compound of interest for $48 \mathrm{~h}$. The cells were rinsed with PBS and lysed with CellLytic buffer at $4^{\circ} \mathrm{C}$. Cell extracts were then centrifuged at $13000 \mathrm{rpm}$ for $10 \mathrm{~min}$ at $4^{\circ} \mathrm{C}$. The protein concentration was adjusted using the Bradford assay and $100 \mu \mathrm{L}$ lysate containing $40 \mu \mathrm{g}$ protein was transferred into a 96 -well plate. $100 \mu \mathrm{L}$ of $5 \mathrm{mM} \mathrm{L}$ DOPA was added, followed by incubation at $37^{\circ} \mathrm{C}$ for $60 \mathrm{~min}$. Dopachrome formation was measured at $475 \mathrm{~nm}$ with a plate reader.

2.8. Mushroom Tyrosinase Assay. The effect of the compounds on mushroom tyrosinase activity was measured using the assay of Zhang et al. [17] with the following modifications. Mushroom tyrosinase was dissolved in $50 \mathrm{mM}$ potassium phosphate buffer ( $\mathrm{pH}$ 6.5) to a concentration of 500 units $/ \mathrm{mL}$. $550 \mu \mathrm{L}$ of $50 \mathrm{mM}$ potassium phosphate and $50 \mu \mathrm{L}$ of the mushroom tyrosinase solution were combined with the test samples in a microfuge tube and incubated for $5 \mathrm{~min}$ at room temperature. $100 \mu \mathrm{L}$ of $1.5 \mathrm{mM} L$-tyrosine was added and the solution was transferred to a 96-well plate. Formation of the dopachrome product was determined by measuring the absorbance at $490 \mathrm{~nm}$ using a microplate reader.

2.9. Purification of Compound 1. The active fraction of the $\mathrm{MeOH}$ extract of $A$. capillaris was separated using a RP18 column with a gradient of $\mathrm{H}_{2} \mathrm{O}-\mathrm{MeOH}(60: 40 \mathrm{v} / \mathrm{v})$ for $50 \mathrm{~min}$ and then changed to $0: 100$ for $20 \mathrm{~min}$ to yield compound 1 ( $2 \mathrm{mg})$.

Isofraxidin 7-O-(6'-O-p-Coumaroyl)- $\beta$-glucopyranoside. Brownish amorphous powder; UV $\lambda_{\max }\left(\mathrm{H}_{2} \mathrm{O}\right)(\log \varepsilon) 300$, 


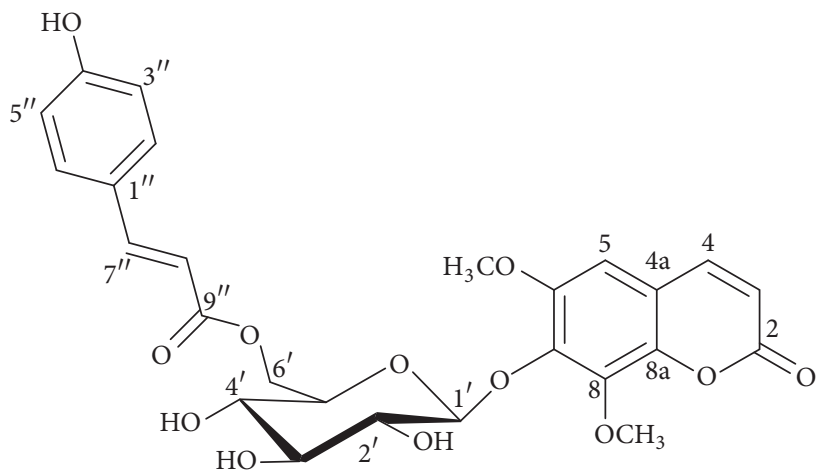

(a)

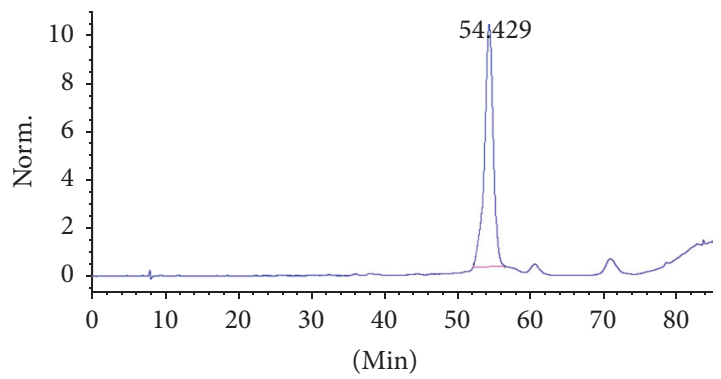

(c)

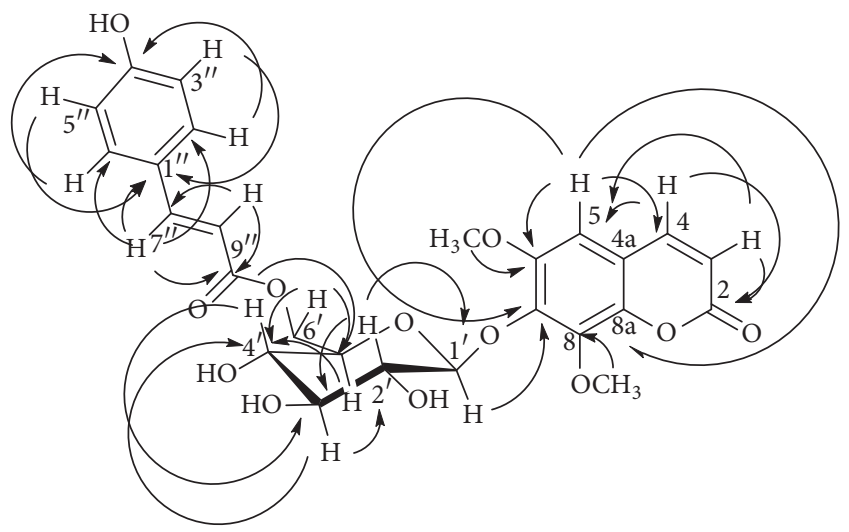

(b)

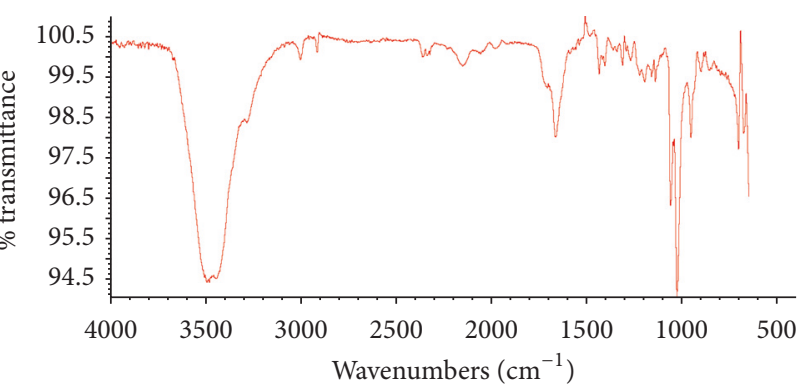

(d)

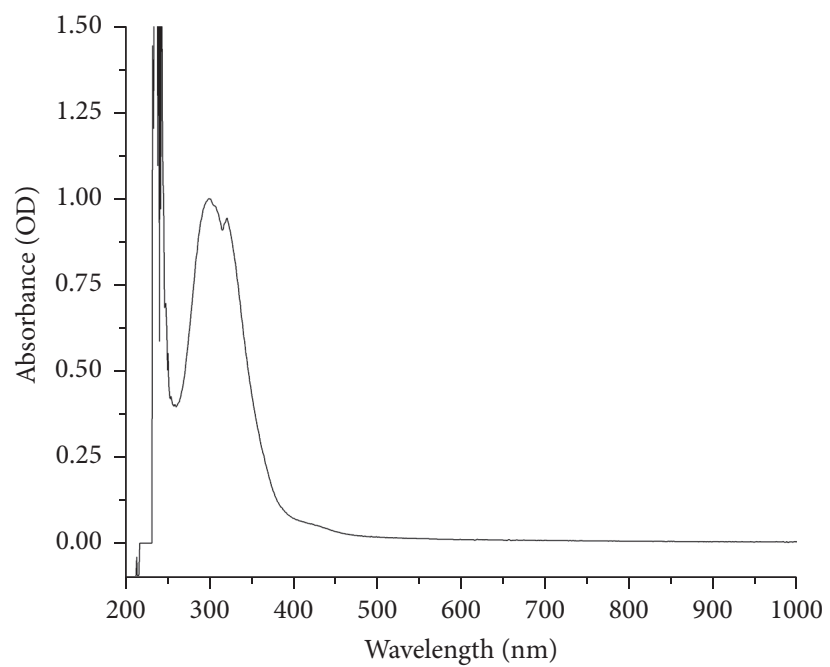

- Absorbance

(e)

FIGURE 1: Characteristics of compound 1 purified from A. capillaris. (a) Chemical structure of compound 1. (b) Key HMBC correlations for compound 1. (c) HPLC chromatogram at $280 \mathrm{~nm}$ of compound 1. (d) Infrared (IR) spectrum and (e) absorption UV spectrum of compound 1 .

304, $322 \mathrm{~nm}$; IR (KBr) $v_{\max }: 3500,1675,1011 \mathrm{~cm}^{-1} ;{ }^{1} \mathrm{H}$ NMR (in $\left.\mathrm{CD}_{3} \mathrm{OD}, 600 \mathrm{MHz}\right) \delta 7.64(1 \mathrm{H}, \mathrm{d}, J=9.6 \mathrm{~Hz}, \mathrm{H}-4), 7.37$ $\left(1 \mathrm{H}, \mathrm{d}, J=15.9 \mathrm{~Hz}, \mathrm{H}-7^{\prime \prime}\right), 7.32\left(2 \mathrm{H}, \mathrm{d}, J=8.7 \mathrm{~Hz}, \mathrm{H}-2^{\prime \prime} / \mathrm{H}-\right.$ $\left.6^{\prime \prime}\right), 6.90(1 \mathrm{H}, \mathrm{s}, \mathrm{H}-5), 6.80\left(2 \mathrm{H}, \mathrm{d}, J=8.7 \mathrm{~Hz}, \mathrm{H}-3^{\prime \prime} / \mathrm{H}-5^{\prime \prime}\right)$, $6.16(1 \mathrm{H}, \mathrm{d}, J=9.6 \mathrm{~Hz}, \mathrm{H}-3), 6.10\left(1 \mathrm{H}, \mathrm{d}, J=15.9 \mathrm{~Hz}, \mathrm{H}-8^{\prime \prime}\right)$, $5.20\left(1 \mathrm{H}, \mathrm{d}, J=7.5 \mathrm{~Hz}, \mathrm{H}-1^{\prime}\right), 4.39(1 \mathrm{H}, \mathrm{dd}, J=11.4,7.2 \mathrm{~Hz}, \mathrm{H}-$ $\left.6^{\prime}\right), 4.34\left(1 \mathrm{H}, \mathrm{dd}, J=11.4,2.0 \mathrm{~Hz}, \mathrm{H}-6^{\prime}\right), 3.99(3 \mathrm{H}, \mathrm{s}, 8-\mathrm{OMe})$, $3.88(3 \mathrm{H}, \mathrm{s}, 6-\mathrm{OMe}), 3.55\left(1 \mathrm{H}, \mathrm{dd}, J=9.0,7.5 \mathrm{~Hz}, \mathrm{H}-2^{\prime}\right), 3.50$ $\left(1 \mathrm{H}, \mathrm{m}, \mathrm{H}-5^{\prime}\right), 3.47\left(1 \mathrm{H}, \mathrm{t}, J=9.0 \mathrm{~Hz}, \mathrm{H}-3^{\prime}\right), 3.40(1 \mathrm{H}, \mathrm{t}, J=$ $9.0 \mathrm{~Hz}, \mathrm{H}-4^{\prime}$ ); ${ }^{13} \mathrm{C} \mathrm{NMR}$ (in $\left.\mathrm{CD}_{3} \mathrm{OD}, 125 \mathrm{MHz}\right) \delta 168.7$ (C$\left.9^{\prime \prime}\right), 162.7(\mathrm{C}-2), 161.5\left(\mathrm{C}-4^{\prime \prime}\right), 151.8(\mathrm{C}-6), 146.5\left(\mathrm{C}-7^{\prime \prime}\right), 145.7$ (C-4), 144.0 (C-8a), 143.1 (C-7), 142.7 (C-8), 131.3 (C-2"/C$\left.6^{\prime \prime}\right), 127.1\left(\mathrm{C}-1^{\prime \prime}\right), 117.1\left(\mathrm{C}-3^{\prime \prime} / \mathrm{C}-5^{\prime \prime}\right), 116.9(\mathrm{C}-4 \mathrm{a}), 115.7$ (C-3), $114.9\left(\mathrm{C}-8^{\prime \prime}\right), 105.9(\mathrm{C}-5), 103.9\left(\mathrm{C}-1^{\prime}\right), 77.9\left(\mathrm{C}-3^{\prime}\right), 75.9\left(\mathrm{C}-5^{\prime}\right)$, $75.7\left(\mathrm{C}-2^{\prime}\right), 72.2\left(\mathrm{C}-4^{\prime}\right), 64.4\left(\mathrm{C}-6^{\prime}\right), 62.5$ (8-OMe), 57.2 (6$\mathrm{OMe})$; HRESI-MS $m / z 529.1346[\mathrm{M}-\mathrm{H}]^{-}\left(\mathrm{C}_{26} \mathrm{H}_{25} \mathrm{O}_{12}\right)$. 
2.10. Quantitative Real-Time PCR Analysis. B16F10 melanocytes were treated with test compounds for $48 \mathrm{~h}$. Total RNA was extracted using the TRI-Solution ${ }^{\mathrm{TM}}$ according to the manufacturer's instructions and quantified using a NanoDrop 2000 spectrophotometer (NanoDrop Technologies). cDNA synthesis was carried out from $1 \mu \mathrm{g}$ RNA using AccuPower ${ }^{\circledR}$ PCR PreMix (Bioneer) following the manufacturer's recommendation. mRNA expression of the MITF gene, tyrosinase gene, and TRP-1 was quantified using a Power SYBT ${ }^{\circledR}$ Green PCR Master Mix (Applied Biosystems). mRNA levels were normalized with $\beta$-actin and fold change of expression was calculated with the $\Delta \Delta C T$ method. The primer sequences were as follows: mouse tyrosinase forward 5' -TACTTGGAACAAGCCAGTCGTATC-3', reverse $5^{\prime}$ ATAGCCTACTGCTAAGCCCAGAGA-3'; mouse TRP-1 forward $5^{\prime}$-AAACCCATTTGTCTCCCAATGA-3', reverse $5^{\prime}$-CGTTTTCCAACGGGAAGGTA- $3^{\prime}$; mouse MITF forward $5^{\prime}$-GGACTTTCCCTTATCCCATCCA-3', reverse $5^{\prime}$ GCCGAGGTTGTTGGTAAAGGT-3 ${ }^{\prime}$. The PCR conditions were $95^{\circ} \mathrm{C}$ for $2 \mathrm{~min}$ followed by 40 cycles of $95^{\circ} \mathrm{C}$ for $30 \mathrm{~s}$, $60^{\circ} \mathrm{C}$ for $1 \mathrm{~min}$, and $72^{\circ} \mathrm{C}$ for $1 \mathrm{~min}$ followed by a final $30 \mathrm{sec}$ extension at $72^{\circ} \mathrm{C}$. Data were analyzed using the Stepone ${ }^{\mathrm{TM}}$ software v2.3 (Applied Biosystems).

2.11. MTT Assay for Cell Viability. Cell viability was assessed using the MTT assay, as previously described [18]. B16-F10 melanocytes were seeded into a 96-well plate at the density of $5 \times 10^{3}$ cells/well for $12 \mathrm{~h}$. Cells were treated with compound or extract for $48 \mathrm{~h}$.

2.12. Maintenance of Zebrafish Fish. The experimental protocols involving zebrafish were approved by the Animal Care and Use Committee of the Gwangju Institute of Technology, Republic of Korea. All methods that utilized zebrafish were carried out in accordance with relevant guidelines and regulations provided by the Gwangju Institute of Science and Technology. Adult zebrafish (Danio rerio) were purchased from a commercial outlet (Lotte Mart, Republic of Korea). 10-15 fishes were maintained in a $5 \mathrm{~L}$ acrylic tank under the following conditions: water temperature $28.5^{\circ} \mathrm{C}$ with a $14 / 10 \mathrm{~h}$ light/dark cycle. Zebrafish were fed twice daily with live brine shrimps (Artemia salina). Fish breeding was carried out using the standard protocol [19] at 9.30 AM in the morning. Embryos were collected within 30 min of spawning.

2.13. Compound Treatment and Evaluation of Pigmentation Phenotype in Zebrafish Embryos. Zebrafish embryos were maintained in $100 \mathrm{~mm}^{2}$ Petri dishes using embryo media $\left(5 \mathrm{mM} \mathrm{NaCl}, 0.17 \mathrm{mM} \mathrm{KCl}, 0.33 \mathrm{mM} \mathrm{CaCl} \cdot 2 \mathrm{H}_{2} \mathrm{O}\right.$, and $0.33 \mathrm{mM} \mathrm{MgSO} \cdot \cdot 7 \mathrm{H}_{2} \mathrm{O}$, to provide a $60 \mathrm{x}$ stock solution) at a density of 70-80 embryos/dish. For compound treatment, embryos were placed in a 96-well plate (3 embryos/well in $200 \mu \mathrm{L}$ embryo media). Compounds were dissolved in $0.1 \%$ DMSO and embryos were treated from 9 to $72 \mathrm{hpf}$ (63 h exposure). The media and embryos were gently stirred and media/compound was replenished daily to ensure an even compound distribution. Effects on the pigmentation were imaged by stereomicroscopy (LEICA DFC425 C; 100x magnification). In all experiments, $75 \mu \mathrm{M}$ PTU was used as a positive control to ablate zebrafish pigmentation without interfering with developmental processes [20]. For microscopy, the embryos were dechorionated using forceps, anesthetized in tricainemethanesulfonate solution (Sigma), and mounted using 3\% methyl cellulose. Melanocyte size and pigmentation intensity were calculated using the Image J software (National Institutes of Health, USA).

2.14. Measurement of Melanin Content and Tyrosinase Activity in Zebrafish. Tyrosinase activity was measured as described previously [21] with the following minor modifications: 40 zebrafish embryos were treated with compound of interest from 9 to $48 \mathrm{hpf}$, followed by homogenization by sonification in CellLytic buffer (pulse on: $10 \mathrm{~s}$, pulse off: $5 \mathrm{~s}, 8 \mathrm{~min}$ in $150 \mu \mathrm{L}$ buffer). The lysate was centrifuged at $13000 \mathrm{rpm}$ for $10 \mathrm{~min}$. the supernatant was collected and protein was quantified using the Bradford assay. $250 \mu \mathrm{g}$ total protein in $100 \mu \mathrm{L}$ buffer was transferred to a 96 -well plate. $100 \mu \mathrm{L} 5 \mathrm{mM} \mathrm{L}$ DOPA was added, followed by incubation for $60 \mathrm{~min}$ at $37^{\circ} \mathrm{C}$. The absorbance was determined at $475 \mathrm{~nm}$ using a microplate reader. The blank sample reading was deleted from each absorbance value, with the final activity expressed as a percentage of the water control.

Melanin content in the zebrafish was measured using the previously described protocol [21]. In brief, protein extracts were prepared at $48 \mathrm{hpf}$ using the same methodology as the tyrosinase assay. After centrifugation, the pellet was collected and dissolved in $200 \mu \mathrm{L} 1 \mathrm{~N} \mathrm{NaOH}$ with $10 \% \mathrm{DMSO}$ for $80^{\circ} \mathrm{C}$ for $60 \mathrm{~min}$, followed by vortexing. Absorbance was measured at $400 \mathrm{~nm}$ using a microplate reader.

2.15. Measurement of Zebrafish Heart Rate. To determine the toxicity of test compounds, the heart rate of the atrium and ventricle was measured for $3 \mathrm{~min}$ at $48 \mathrm{hpf}$ to assess toxicity, as previously described [22] using a Zeiss Stemi 2000-C stereomicroscope.

2.16. Melanocyte Counting Assay. To count melanocytes, embryos were exposed to the fish room lighting. This induces contraction of the melanin within the melanocytes [23]. Embryos were then fixed in $4 \%$ paraformaldehyde and imaged using stereomicroscopy. Melanocytes were counted in the head region of the embryos.

2.17. Statistical Analysis. Data were evaluated for significance using Student's $t$-test (Microsoft Excel 2016). A p value of less than 0.05 was considered to be significant. Data are expressed as the means \pm SEM of three independent experiments, unless otherwise indicated.

\section{Results}

3.1. Purification and Isolation of Compound 1 from the A. capillaris Plant Extract. An active fraction from A. capillaris was previously shown to regulate melanin synthesis [24]. Preparative reversed-phase HPLC was performed to purify additional compounds from this active fraction. A $2.0 \mathrm{mg}$ compound (termed compound 1; Figures 1(a) and 1(b)) was purified. The chromatogram obtained for compound 
TABLE 1: ${ }^{1} \mathrm{H}$ and ${ }^{13} \mathrm{C}$ NMR spectroscopic data $\left(600 \mathrm{MHz}\right.$, methanol- $\left.d_{4}\right)$ for isofraxidin $7-O-\left(6^{\prime}\right.$ - $O$ - $p$-coumaroyl)- $\beta$-glucopyranoside.

\begin{tabular}{|c|c|c|c|}
\hline Position & $\delta_{\mathrm{H}}(J$ in $\mathrm{Hz})$ & $\delta_{\mathrm{C}}$ & $\mathrm{HMBC}^{\mathrm{a}}$ \\
\hline 2 & - & 162.7 & \\
\hline 3 & $6.161 \mathrm{H}, \mathrm{d}(9.6)$ & 115.7 & $C-2,4 a$ \\
\hline 4 & $7.641 \mathrm{H}, \mathrm{d}(9.6)$ & 145.7 & $\mathrm{C}-2,5$ \\
\hline $4 a$ & - & 116.9 & \\
\hline 5 & $6.901 \mathrm{H}, \mathrm{s}$ & 105.9 & $\mathrm{C}-4,6,7,8 \mathrm{a}$ \\
\hline 6 & - & 151.8 & \\
\hline 7 & - & 143.1 & \\
\hline 8 & - & 142.7 & \\
\hline $8 a$ & - & 144.0 & \\
\hline $1^{\prime}$ & $5.201 \mathrm{H}, \mathrm{d}(7.5)$ & 103.9 & $\mathrm{C}-7$ \\
\hline $2^{\prime}$ & $3.551 \mathrm{H}, \mathrm{dd}(7.5,9.0)$ & 75.7 & $\mathrm{C}-1^{\prime}, 3^{\prime}$ \\
\hline $3^{\prime}$ & $3.471 \mathrm{H}, \mathrm{t}(9.0)$ & 77.9 & $\mathrm{C}-2^{\prime}, 4^{\prime}$ \\
\hline $4^{\prime}$ & $3.40(1 \mathrm{H}, \mathrm{t}, 9.0)$ & 72.2 & $C-3^{\prime}, 5^{\prime}$ \\
\hline $5^{\prime}$ & $3.50 \mathrm{1H}, \mathrm{m}$ & 75.9 & $\mathrm{C}-4^{\prime}$ \\
\hline \multirow[t]{2}{*}{$6^{\prime}$} & $4.391 \mathrm{H}, \mathrm{dd}(11.4,7.2)$ & \multirow{2}{*}{64.4} & \multirow[t]{2}{*}{$C-4^{\prime}, 5^{\prime}$} \\
\hline & $4.341 \mathrm{H}, \mathrm{dd}(11.4,2.0)$ & & \\
\hline $1^{\prime \prime}$ & - & 127.1 & \\
\hline $2^{\prime \prime} / 6^{\prime \prime}$ & $7.322 \mathrm{H}, \mathrm{d}(8.7)$ & 131.3 & $\mathrm{C}-4^{\prime \prime}$ \\
\hline $3^{\prime \prime} / 5^{\prime \prime}$ & $6.802 \mathrm{H}, \mathrm{d}(8.7)$ & 117.1 & $\mathrm{C}-1^{\prime \prime}, 4^{\prime \prime}$ \\
\hline $4^{\prime \prime}$ & - & 161.5 & \\
\hline $7^{\prime \prime}$ & $7.37 \mathrm{lH}, \mathrm{d}(15.9)$ & 146.5 & $C-1^{\prime \prime}, 2^{\prime \prime} / 6^{\prime \prime}, 9^{\prime \prime}$ \\
\hline $8^{\prime \prime}$ & $6.10 \mathrm{1H}, \mathrm{d}(15.9)$ & 114.9 & $\mathrm{C}-7^{\prime \prime}, 9^{\prime \prime}$ \\
\hline $9^{\prime \prime}$ & - & 168.7 & \\
\hline 6-OMe & $3.883 \mathrm{H}, \mathrm{s}$ & 57.2 & C-6 \\
\hline 8-OMe & $3.993 \mathrm{H}, \mathrm{s}$ & 62.5 & C-8 \\
\hline
\end{tabular}

${ }^{\mathrm{a}} \mathrm{HMBC}$ correlations for compound $\mathbf{1}$.

1 extracted with a retention time $54.428 \mathrm{~min}$ is shown in Figure 1(c). Compound 1 was identified and characterized on the basis of complementary information provided by ESIMS detectors. The structure of the isolate was identified by spectroscopic analysis ( ${ }^{1} \mathrm{H}$ NMR), as a novel compound. The IR and UV spectra for purified compound $\mathbf{1}$ are shown in Figures $1(\mathrm{~d})$ and $1(\mathrm{e})$. This compound was identified and characterized using complementary information provided by the ESI-MS detectors. The appearance of isolated compound 1 was a pale brown, amorphous powder. Compound 1 was assigned the molecular formula, $\mathrm{C}_{26} \mathrm{H}_{25} \mathrm{O}_{12}$, based on the HRESIMS spectra of the compound obtained in the negative ion mode $\left(m / z 529.1346[\mathrm{M}-\mathrm{H}]^{-}\right.$. calcd for $\left.\mathrm{C}_{26} \mathrm{H}_{25} \mathrm{O}_{12}\right)$. Compound 1 exhibited UV absorption bands at 300, 304, and $322 \mathrm{~nm}$ with IR absorption bands corresponding to hydroxy $\left(3500 \mathrm{~cm}^{-1}\right)$ and carbonyl $\left(1675 \mathrm{~cm}^{-1}\right)$. The $1 \mathrm{D}$ NMR spectra of compound 1 exhibited signals for a coumarin moiety, a $p$ coumaroyl moiety, and a $\beta$-glucopyranose unit. Compound 1 showed two doublets at $\delta_{\mathrm{H}} 7.64(1 \mathrm{H}, \mathrm{d}, J=9.6 \mathrm{~Hz}, \mathrm{H}-$ 4), $\delta_{\mathrm{H}} 6.16(1 \mathrm{H}, \mathrm{d}, J=9.6 \mathrm{~Hz}, \mathrm{H}-3)$, and a carbonyl ester at $\delta_{\mathrm{C}} 162.7(\mathrm{C}-2)$ ascribable to the coumarin moiety and exhibited the presence of one $\beta$-glucopyranose unit from the anomeric signals at $\delta_{\mathrm{H}} 5.20\left(1 \mathrm{H}, \mathrm{d}, J=7.8 \mathrm{~Hz}, \mathrm{H}-1^{\prime}\right)$ including hydroxyl methine signals at $\delta_{\mathrm{H}} 3.40 \sim 3.55$ with vicinal coupling constants $(J=9.0 \mathrm{~Hz})$ between two axial hydrogens. The signals of $p$-coumaroyl moiety were assigned to symmetric doublets at $\delta_{\mathrm{H}} 7.32(2 \mathrm{H}, \mathrm{d}, J=8.7 \mathrm{~Hz}, \mathrm{H}-$ $\left.2^{\prime \prime} / \mathrm{H}-6^{\prime \prime}\right)$ and $6.80\left(2 \mathrm{H}, \mathrm{d}, J=8.7 \mathrm{~Hz}, \mathrm{H}-3^{\prime \prime} / \mathrm{H}-5^{\prime \prime}\right)$, as well as proton doublets showing trans-configuration at $\delta_{\mathrm{H}} 7.37$ $\left(1 \mathrm{H}, \mathrm{d}, J=15.9 \mathrm{~Hz}, \mathrm{H}-7^{\prime \prime}\right)$ and $6.10(1 \mathrm{H}, \mathrm{d}, J=15.9 \mathrm{~Hz}, \mathrm{H}-$ $\left.8^{\prime \prime}\right)$. Two aromatic carbon signals at $\delta_{\mathrm{C}} 161.5\left(\mathrm{C}-4^{\prime \prime}\right)$ and $127.1\left(\mathrm{C}-1^{\prime \prime}\right)$ were correlated to two symmetric doublet proton signals and proton doublets with trans-configuration of $p$ coumaroyl moiety in the heteronuclear multiple bond connectivity (HMBC) spectrum. In addition, long-range HMBC correlations were, respectively, observed between anomeric proton $\left(\mathrm{H}-1^{\prime}\right)$ and an oxygenated aromatic carbon at $\delta_{\mathrm{C}} 143.1$ $(\mathrm{C}-7)$, between a methoxy proton signal at $\delta_{\mathrm{H}} 3.88(3 \mathrm{H}, \mathrm{s})$ and C-6 carbon and a methoxy proton signal at $\delta_{\mathrm{H}} 3.99(3 \mathrm{H}$, s) to C-8 aromatic carbon (Figure 1(b)). Moreover, downfieldshifted two oxygenated methylene signals at $\delta_{\mathrm{H}} 4.39,4.43(\mathrm{H}-$ $\left.6^{\prime}\right)$ and $\delta_{\mathrm{C}} 64.4\left(\mathrm{C}-6^{\prime}\right)$ indicated that a carbonyl ester (C$\left.9^{\prime \prime}\right)$ group of $p$-coumaroyl moiety was attached with $C-6^{\prime}$ of the glucose unit. On the basis of this data, the structure of compound 1 was elucidated to be isofraxidin $7-O-\left(6^{\prime}-\right.$ $O$ - $p$-coumaroyl)- $\beta$-glucopyranoside. The ${ }^{1} \mathrm{H}$ and ${ }^{13} \mathrm{C} \mathrm{NMR}$ spectroscopic data $\left(600 \mathrm{MHz}\right.$, methanol- $\left.d_{4}\right)$ for compound 1 are shown in Table 1.

3.2. Effect of Compound 1 on Melanin Production in B16F10 Melanocytes. To investigate whether compound $\mathbf{1}$ regulates melanogenesis, melanin levels in B16F10 cells were 

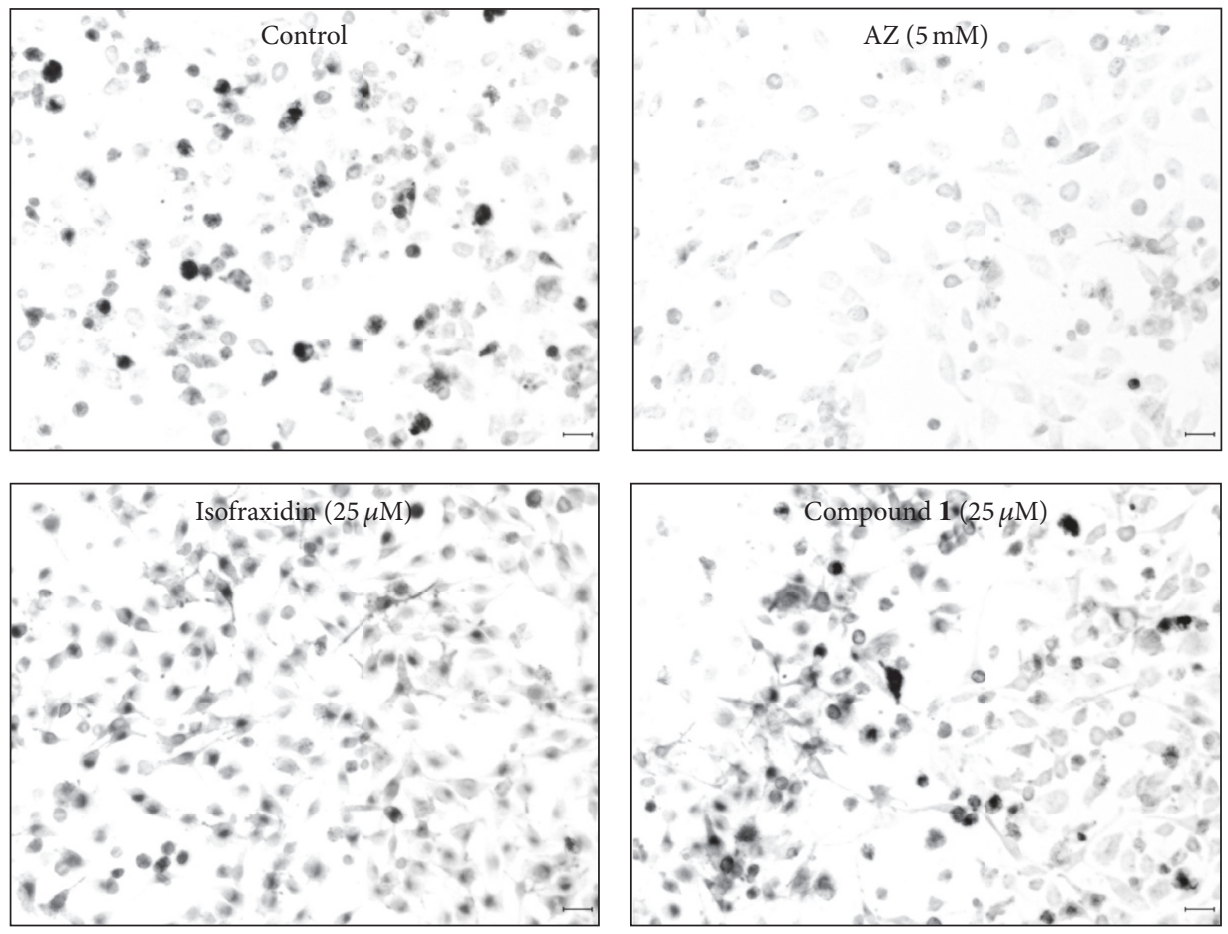

(a)

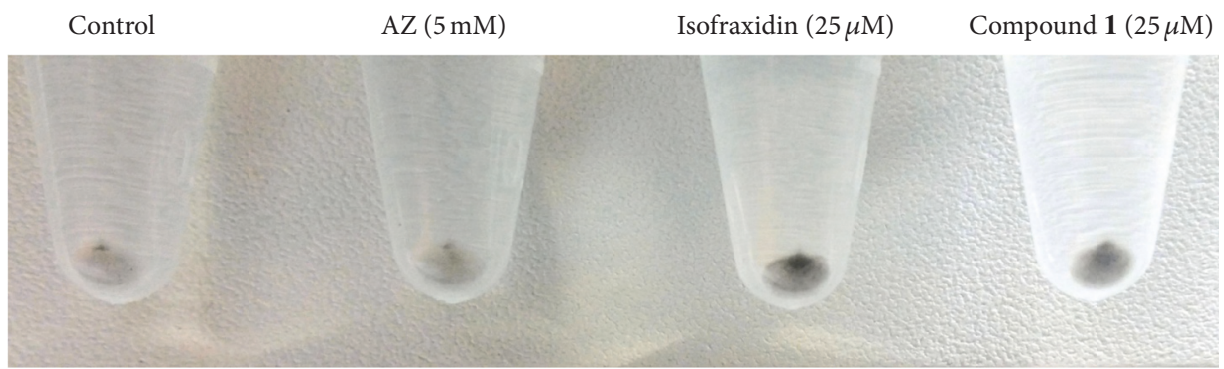

(b)
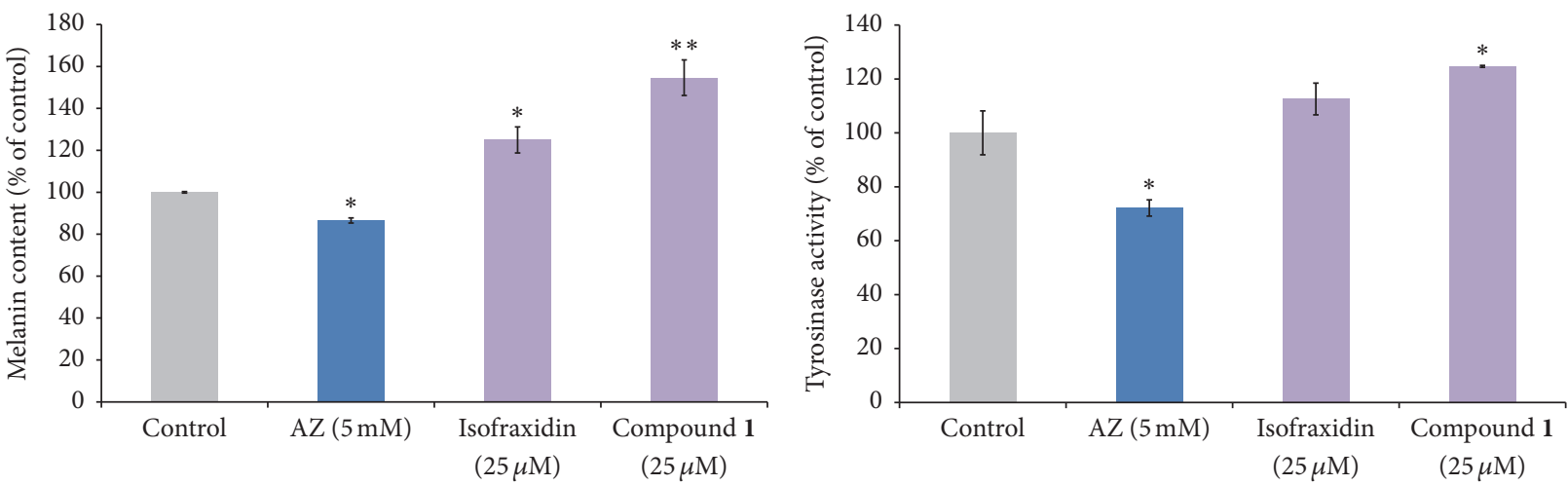

(c)

(d)

FIGURE 2: Effect of compound 1 on melanin content in cultured B16F10 melanoma cells. (a) Cell images with or without the indicated treatment were taken using a digital camera (magnification 100x). Scale bar $=20 \mu \mathrm{m}$. Untreated B16F10 show characteristic fibroblastic and spherical cell morphology. Isofraxidin and IFG treated B16F10 melanocytes show increased darkening of the cytoplasm compared to control cells after exposure to $25 \mu \mathrm{M}$ compound $\mathbf{1}$ for 2 days. (b) Isofraxidin and compound $\mathbf{1}$ treated B16F10 cell pellets are more pigmented compared to untreated cells. (c) B16F10 cells were treated with compound $\mathbf{1}$ for $48 \mathrm{~h}$ at $37^{\circ} \mathrm{C}$ showing increased pigmentation in the melanocytes. (d) B16F10 melanocytes were treated with isofraxidin and compound $\mathbf{1}$ at the indicated concentrations for 2 days. Compound $\mathbf{1}$ also increased tyrosinase activity. ${ }^{*} p<0.05$ compared to the untreated control. ${ }^{* *} p<0.05$ compared to isofraxidin treatment. AZ $=$ azelaic acid. 

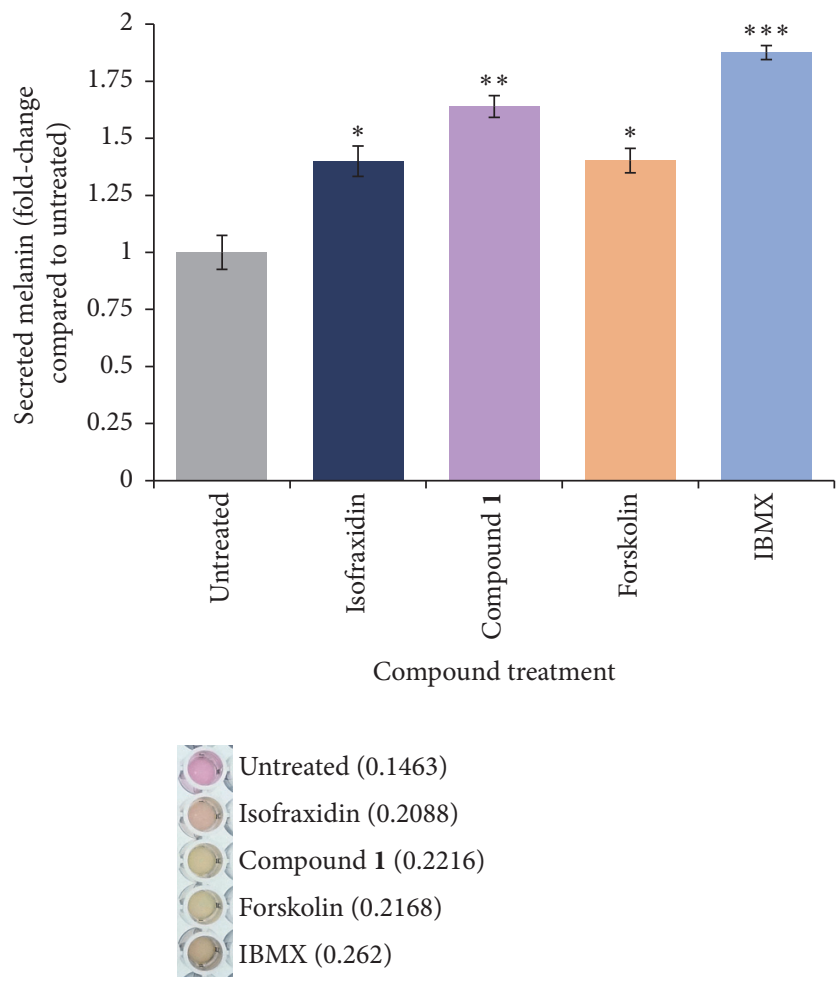

(a)

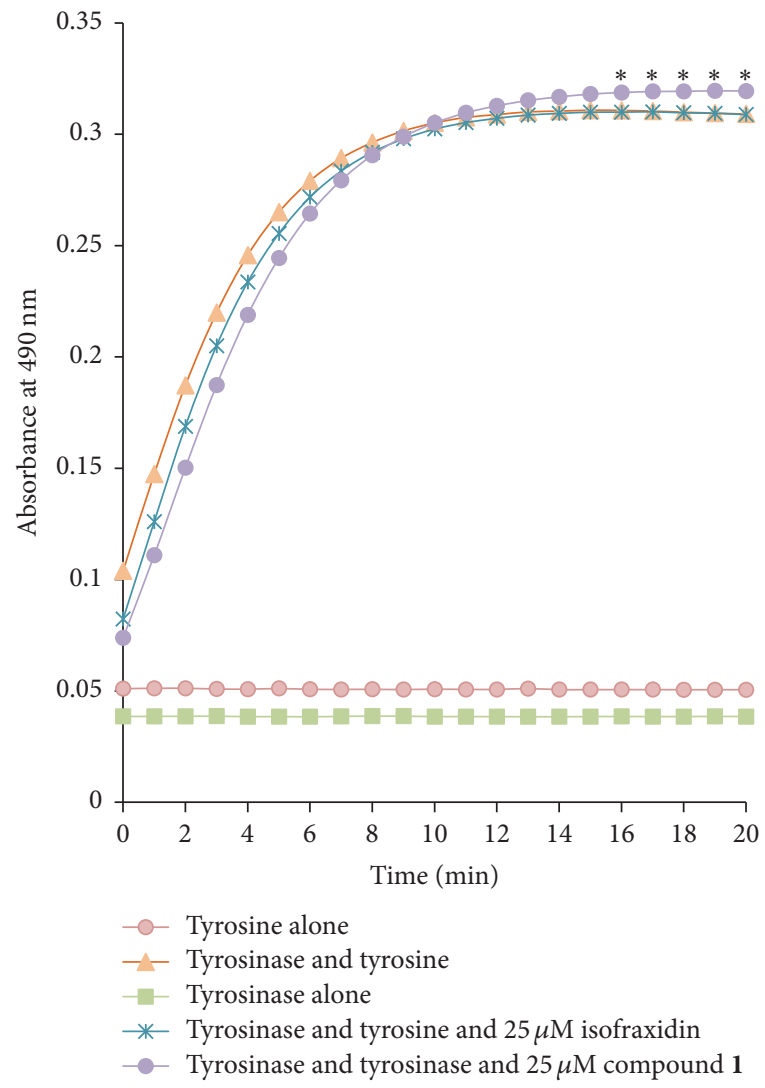

(b)

FIGURE 3: Compound 1 increases melanin secretion and increases the activity of mushroom tyrosinase. (a) Effect of $25 \mu \mathrm{M}$ compound 1 and $25 \mu \mathrm{M}$ isofraxidin on melanin secretion by B16F10 melanocytes. Culture media were collected after $60 \mathrm{~h}$ treatment. For comparison with known inducers of pigmentation, melanocytes were treated with $100 \mu \mathrm{M}$ IBMX or $5 \mu \mathrm{M}$ forskolin, as previously described [13, 14]. Error = SD; ${ }^{*} p<0.05$ for increased melanin secretion compared to untreated cells; ${ }^{* *} p<0.05$ for increased melanin secretion compared to isofraxidin; ${ }^{* * *} p<0.05$ for increased melanin secretion compared to compound $\mathbf{1}$. (b) Compound $\mathbf{1}$, but not isofraxidin, increases tyrosinase activity. Mushroom tyrosinase was used to measure tyrosinase activity in a cell-free assay. Error $=\mathrm{SD} ;{ }^{*} p<0.05$ compared to tyrosinase plus tyrosine.

measured after compound treatment. Along with compound 1, we also tested the effects of isofraxidin (7-hydroxy-6,8dimethoxycoumarin), the parent compound of compound $\mathbf{1}$. The previously characterized melanogenic inhibitor, azelaic acid (AZ) [25], was used as a control. Addition of compound 1 to melanocytes stimulated melanin production (Figures $2(\mathrm{a})$ and 2(b)). Compound 1 significantly increased melanogenesis in a dose-dependent manner (Figure 2(c)). Moreover, melanocyte tyrosinase activity was also stimulated dosedependently (Figure 2(d)). The parent compound, isofraxidin, also significantly increased melanin production, but not tyrosinase activity in B16F10 melanocytes (Figures 2(c) and 2(d)).

After treatment with melanogenic compounds, B16F10 cells are known to increase secretion of melanin into the culture media [15]. It was observed that compound $\mathbf{1}$ treatment increased melanin secretion by the melanocytes
(Figure 3(a)). This secretion was greater than that observed in isofraxidin treated melanocytes. Compared to known inducers of pigmentation, IBMX [14] produced a greater effect on pigmentation than compound $\mathbf{1}$, whereas forskolin [13] produced a lesser effect.

3.3. Compound 1 Increases the Activity of Mushroom Tyrosinase. To further characterize the mechanisms by which compound 1 increases melanocyte pigmentation, a cell-free mushroom tyrosinase assay was performed. It was observed that compound 1 produced a significant increase in tyrosinase activity, which could be detected after 15 min of incubation (Figure 3(b)). In contrast, the parent compound, isofraxidin, did not affect tyrosinase activity.

3.4. Compound 1 Upregulates the Expression of MITF and Tyrosinase in Melanocytes. Three key regulatory genes for 


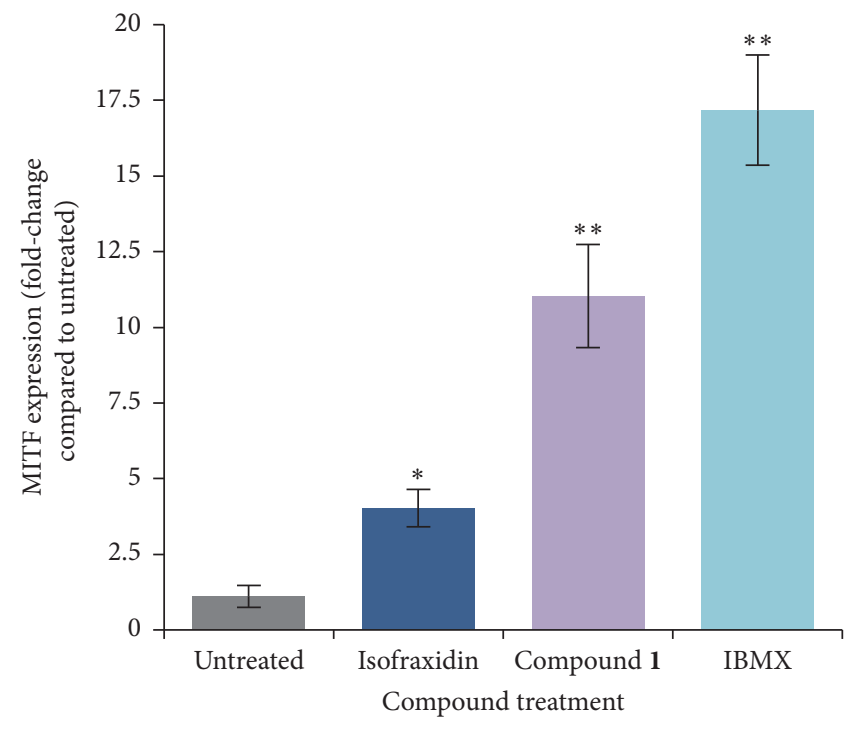

(a)

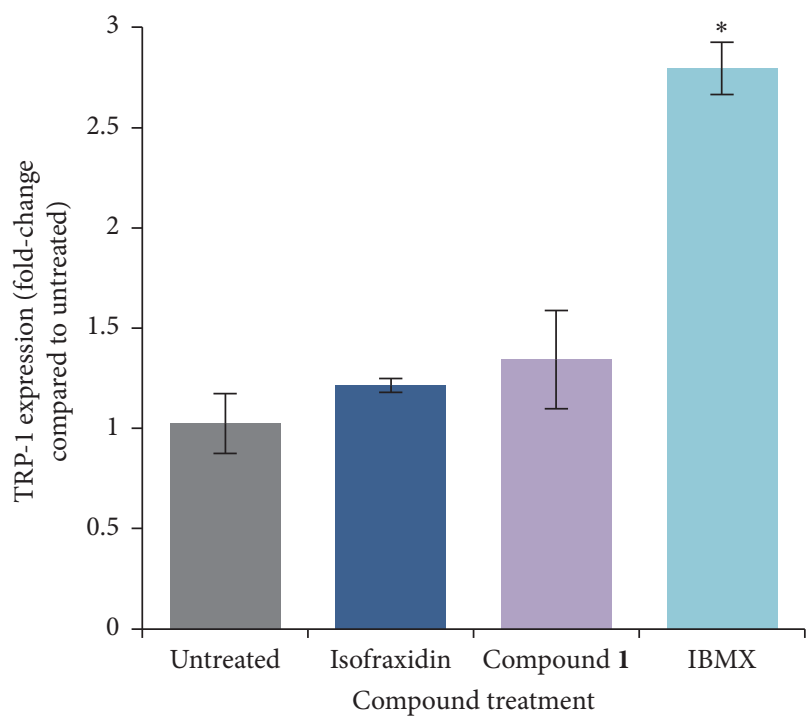

(b)

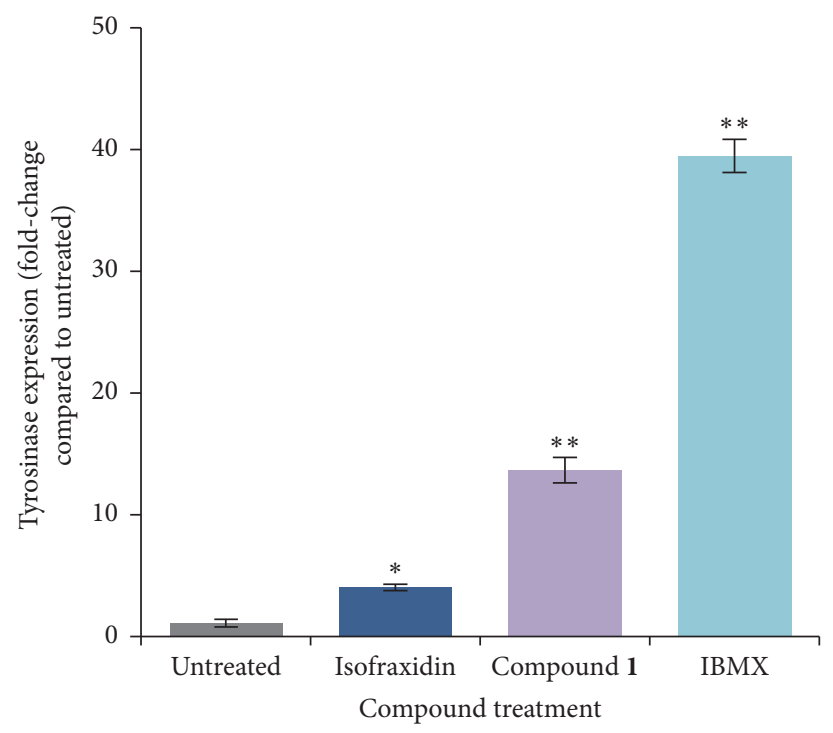

(c)

FIGURE 4: Real-time PCR analysis of MIFT, TRP-1, and tyrosinase gene expression in B16F10 melanocytes treated with $25 \mu \mathrm{M}$ isofraxidin, $25 \mu \mathrm{M}$ compound 1 or IBMX for $48 \mathrm{~h}$. (a) Expression of MIFT. ${ }^{*} p<0.05$ compared to untreated cells; ${ }^{* *} p<0.05$ for increased expression compared to isofraxidin treated cells. (b) Expression of TRP-1. ${ }^{*} p<0.05$ compared to untreated cells. (c) Expression of tyrosinase. ${ }^{*} p<0.05$ compared to untreated cells; ${ }^{* *} p<0.05$ for increased expression compared to isofraxidin treated cells.

melanogenesis are microphthalmia-associated transcription factor (MITF), tyrosinase-related protein-1 (TRP-1), and tyrosinase [16, 26, 27]. Treatment of B16F10 melanocytes with compound 1 for $48 \mathrm{~h}$ produced an increase in the expression of MITF and tyrosinase, but not TRP-1 (Figures 4(a)-4(c)). The increase in MITF and tyrosinase expression was greater than that observed after treatment with the parent compound, isofraxidin, at the same concentration.

\subsection{Effect of Compound 1 on Zebrafish Skin Pigmenta-} tion, Melanin Content, and Tyrosinase Activity. To assess the effect of compound $\mathbf{1}$ on pigmentation in vivo, we employed the zebrafish larvae model, which has proved useful for characterizing novel regulators of pigmentation [28]. Phenylthiourea (PTU), a known tyrosinase inhibitor [29], was tested as a positive control to assess in vivo alterations in pigmentation (Figure 5).

We found out that PTU dose-dependently abrogated pigmentation (Figure 5).

We evaluated the toxicity indicators, mortality rate, and heart rate $[22,30]$ in treated zebrafish embryos to identify the safe and effective concentration of compound 1 (Figure 6). $9 \mathrm{hpf}$ embryos were treated with compound. Greater than $90 \%$ of the treated embryos survived, which did not differ significantly from the control group. Based on this toxicity data, the effect compound $\mathbf{1}$ on pigmentation in the zebrafish 

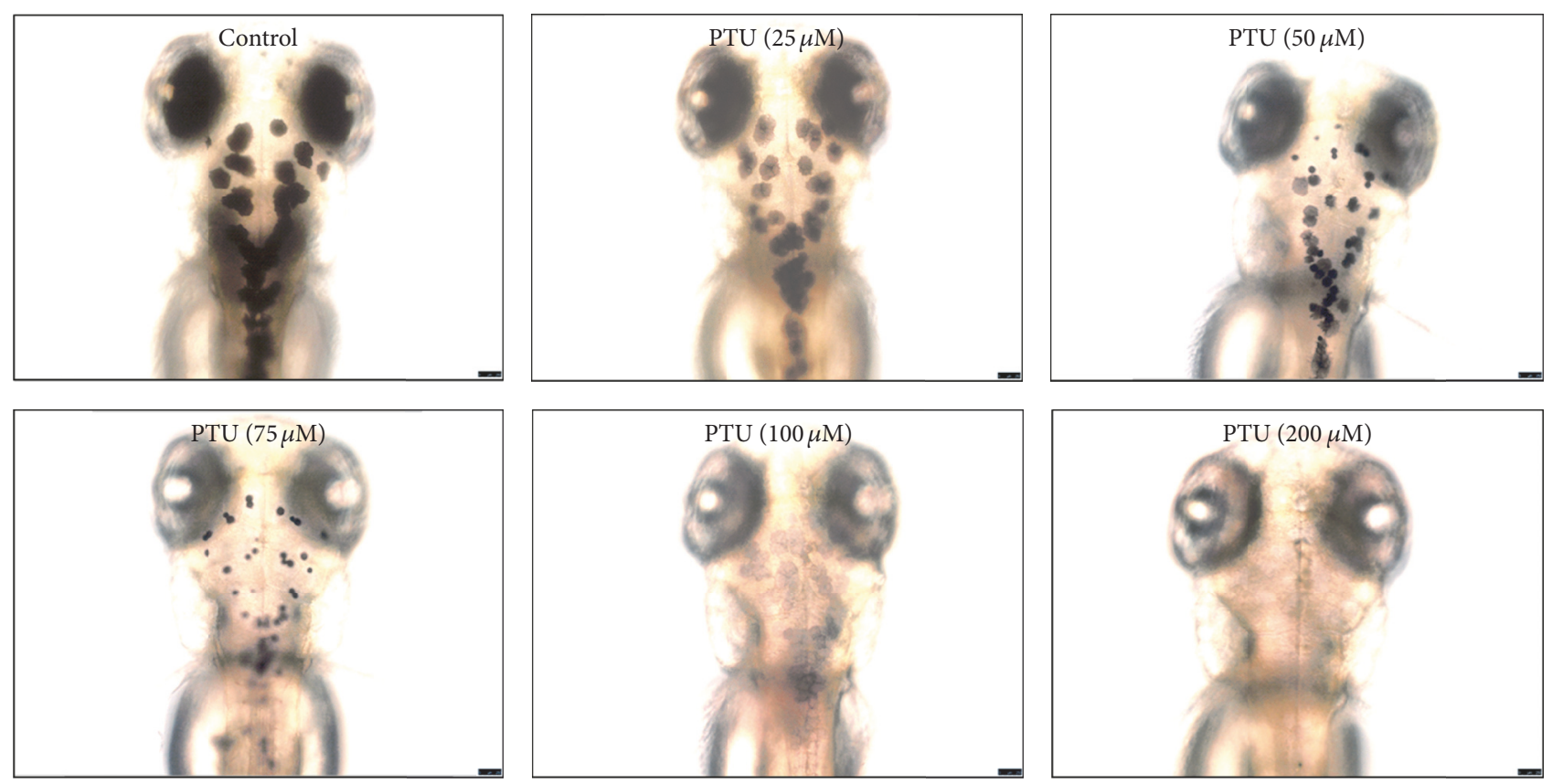

FIGURE 5: Dose-dependent effect of PTU on pigmentation in zebrafish embryos. Zebrafish were treated with PTU at concentrations of 25, 50, 75,100 , and $200 \mu \mathrm{M}$. PTU treatment suppressed the production of black pigment spots (melanization) in the larva. Scale bar $=250 \mu \mathrm{m}$.

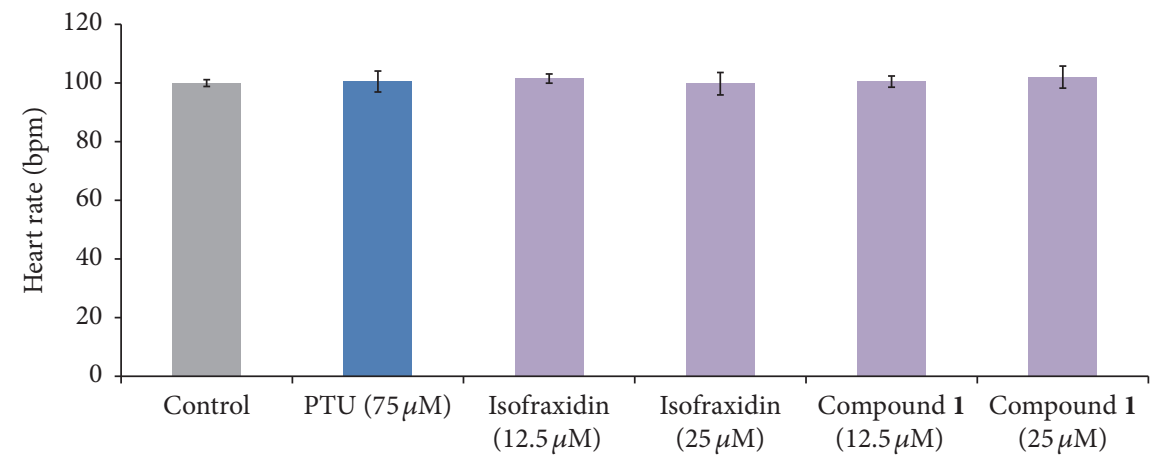

FIGURE 6: Effect of compound 1 on average heart beat per minute (bpm) zebrafish embryos. The bpm of 48 hpf zebrafish embryos was assessed by visual examination.

was tested at the $12.5 \mu \mathrm{M}$ and $25 \mu \mathrm{M}$ dose (Figure $7(\mathrm{a})$ ). Compound 1 and isofraxidin were observed to increase melanocyte size in the zebrafish larvae. To quantify melanin content, 40 zebrafish larvae were treated with compound $\mathbf{1}$ or isofraxidin. It was observed that compound 1 increased melanin content at the $25 \mu \mathrm{M}$ dose (Figure $7(\mathrm{~b})$ ). The tyrosinase activity was carried out in treated zebrafish larvae (Figure $7(\mathrm{c})$ ). It was observed that the 12.5 and $25 \mu \mathrm{M}$ doses of compound 1 increased tyrosinase activity (Figure $7(\mathrm{c})$ ). Overall, these findings indicate that the hyperpigmentation effect of compound $\mathbf{1}$ is mediated through the stimulation of tyrosinase activity.

3.6. Effect of Compound $\mathbf{1}$ on Zebrafish Melanocyte Pigmentation. To further characterize the effect of compound 1 on melanocyte pigmentation, we measured melanocyte development in compound treated and untreated zebrafish skin. Zebrafish melanocytes develop from melanoblasts at about $25 \mathrm{hpf}$, and by $60 \mathrm{hpf}$ the larval pigment pattern is established [31]. We observed that zebrafish embryos treated with isofraxidin or compound $\mathbf{1}$ showed increased numbers of visible melanocytes compared to the control embryo (Figure 8(a)). Moreover, isofraxidin or compound $\mathbf{1}$ also produced an increase in the melanocyte area in the treated embryos (Figure 8(b)).

\section{Discussion}

Our study describes the discovery of compound $\mathbf{1}$ as a hyperpigmentation agent isolated from $A$. capillaris that is effective in an in vivo system. Compound $\mathbf{1}$ increased pigmentation without producing toxicity.

Compound 1 produced greater effects on melanin production and secretion in melanocytes compared to the parent compound, isofraxidin (Figures 2(c) and 3(a)). To our knowledge, there is no previous report that isofraxidin 

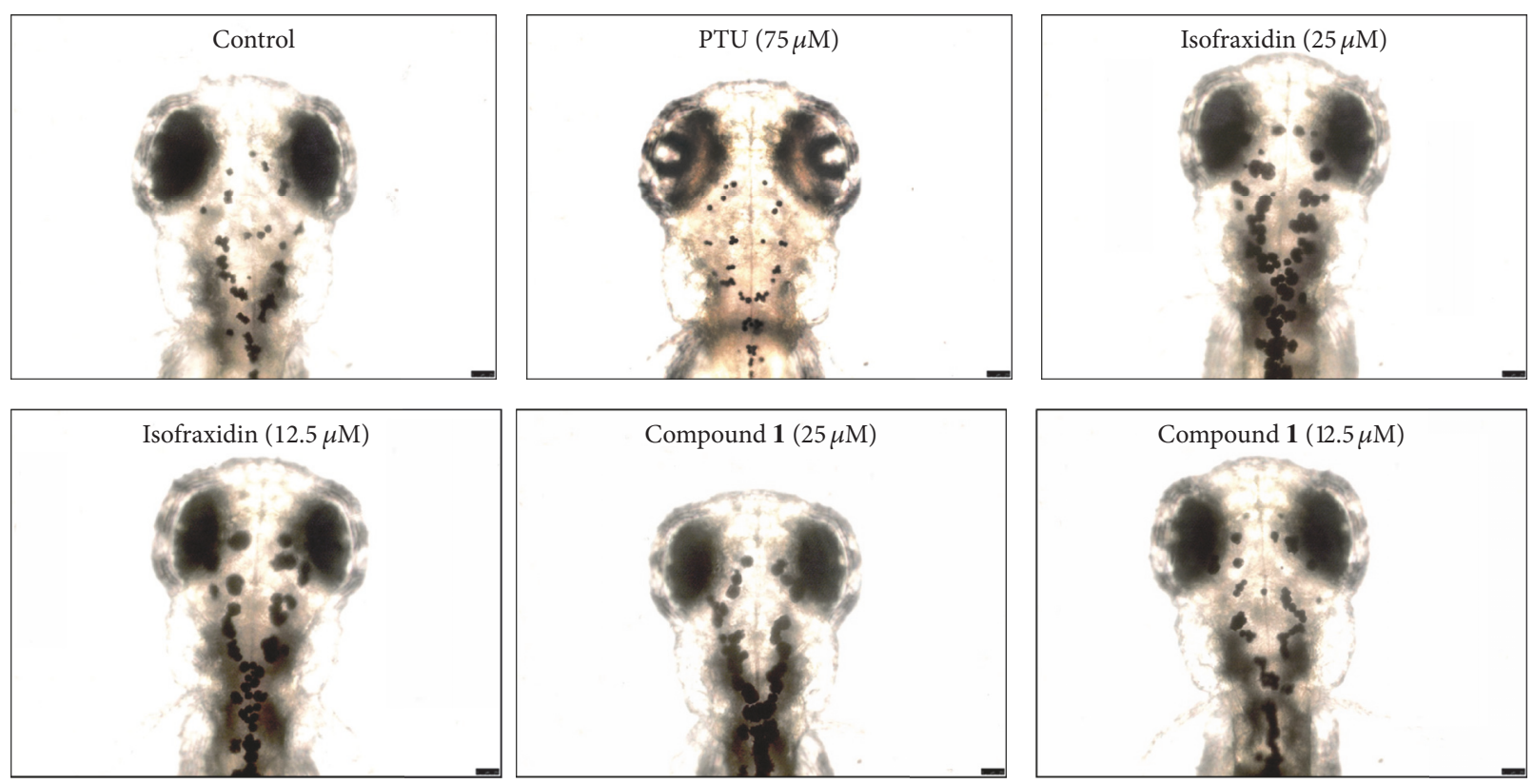

(a)

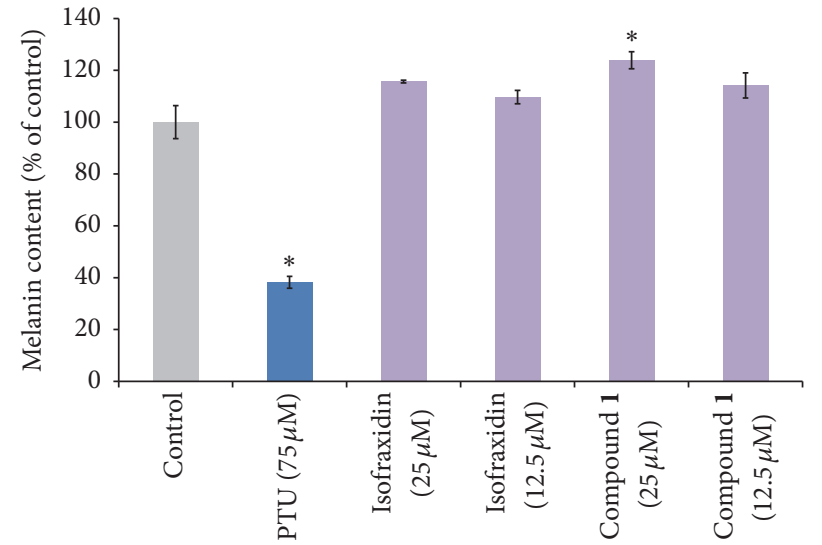

(b)

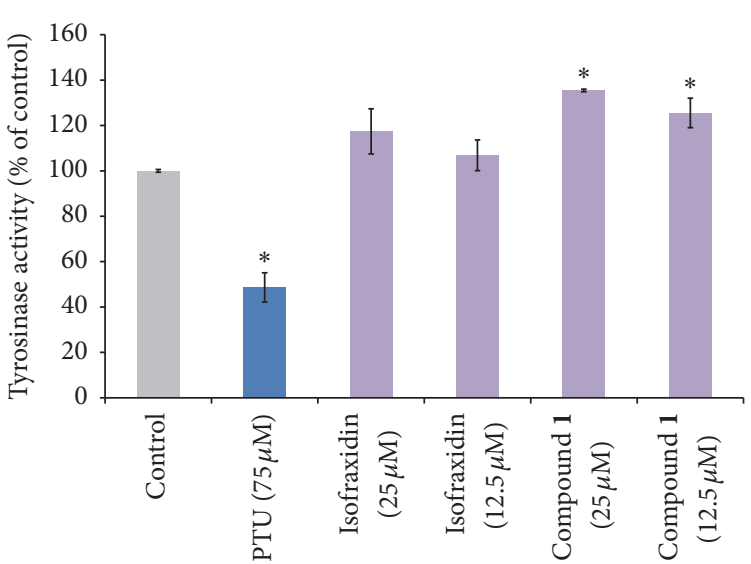

(c)

FIGURE 7: Effect of compound 1 on pigmentation in zebrafish embryos. (a) 9 hpf embryos were treated with PTU and two concentrations of isofraxidin or compound $\mathbf{1}(12.5 \mu \mathrm{M}$ and $25 \mu \mathrm{M})$. Dorsal view of treated and untreated embryos at $72 \mathrm{hpf}$ by stereomicroscope (magnification 100x). Isofraxidin and compound 1 increased melanocyte pigmentation. Scale bar $=250 \mu \mathrm{m}$. (b) Melanin content in zebrafish larvae treated with compound $\mathbf{1}$ or isofraxidin. $25 \mu \mathrm{M}$ compound $\mathbf{1}$ significantly increased melanin content in the zebrafish larvae. (c) Tyrosinase activity in zebrafish larvae treated with compound $\mathbf{1}$ or isofraxidin. $12.5 \mu \mathrm{M}$ or $25 \mu \mathrm{M}$ compound $\mathbf{1}$ significantly increased tyrosinase activity in the zebrafish larvae. ${ }^{*} p<0.05$ compared to the untreated control larvae.

can increase pigmentation. Our results show that isofraxidin can increase melanin content in melanocytes (Figure 2(c)). However, tyrosinase activity was not affected (Figure 2(d)). In contrast, compound $\mathbf{1}$ significantly increased melanin content in melanocytes compared to isofraxidin (Figures 2(c) and $2(\mathrm{~d})$ ). A potential mechanism to explain the stronger pigmentation effect of compound $\mathbf{1}$ is the higher induction of pigmentation gene expression (MITF and tyrosinase) relative to isofraxidin (Figures 4 (a) and 4(c)). In addition, compound 1 increased the activity of tyrosinase in the cellfree assay, which was not observed after isofraxidin treatment (Figure $3(\mathrm{~b})$ ). In the zebrafish pigmentation system, both isofraxidin and compound $\mathbf{1}$ increased melanocyte number and area (Figures 8(a) and 8(b)). However, only compound 1 produced significant increases in melanocyte accumulation and tyrosinase activity in this animal model (Figures 7(b) and $7(\mathrm{c})$ ) indicating that compound $\mathbf{1}$ is a more potent inducer of pigmentation compared to isofraxidin.

In summary, we have discovered that compound $\mathbf{1}$ is a novel, nontoxic pigmentation enhancer that is effective in vivo. Compound $\mathbf{1}$ targets the expression of MITF and tyrosinase expression/activity. These results indicate that this natural product can be further developed as a therapeutic for treating hypopigmentation disorders. 


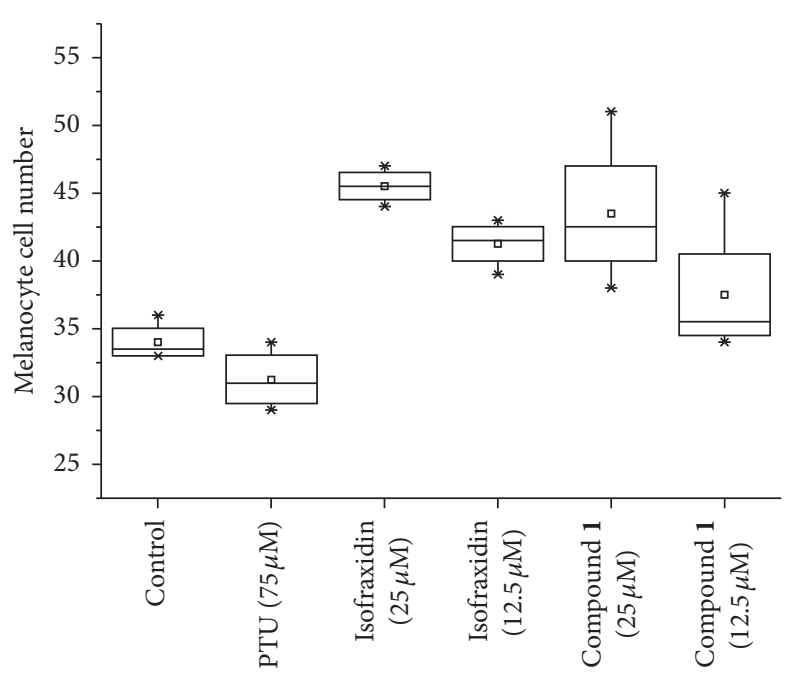

(a)

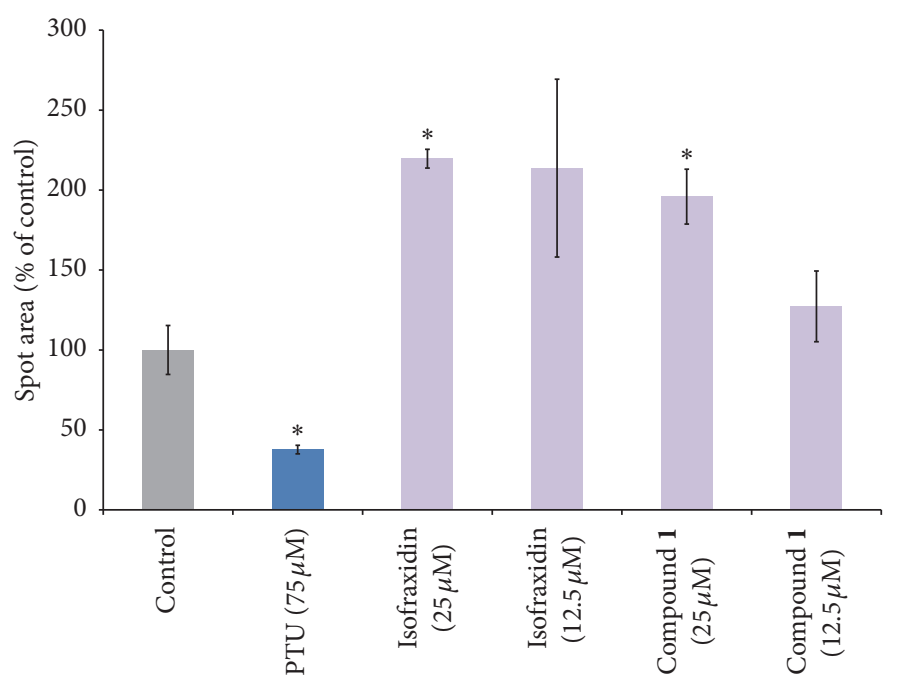

(b)

FIGURE 8: Effect of compound $\mathbf{1}$ on melanocyte numbers and surface area in zebrafish embryos. (a) Box and whisker plot of melanocyte numbers in the head region in embryos treated with PTU, isofraxidin, or compound $\mathbf{1}$ at $48 \mathrm{hpf}$. (b) Surface area of melanocytes in the treated and untreated embryos at 48 hpf. $^{*} p<0.05$ compared to the untreated larva.

$\begin{array}{ll}\text { Abbreviations } \\ { }^{1} \mathrm{H} \text { NM: } & \text { Proton nuclear magnetic resonance } \\ { }^{13} \mathrm{C} \mathrm{NMR:} & \text { Carbon nuclear magnetic resonance } \\ \text { A. capillaris: } & \text { Artemisia capillaris Thunberg } \\ \text { ACN: } & \text { Acetonitrile } \\ \text { AZ: } & \text { Azelaic acid } \\ \text { DMSO: } & \text { Dimethylsulfoxide } \\ \text { Hpf: } & \text { Hours postfertilization } \\ \text { HPLC: } & \text { High performance liquid chromatography } \\ \text { IBMX: } & \text { 3-Isobutyl-1-methylxanthine } \\ \text { L-DOPA: } & \text { L-3,4-Dihydroxyphenylalanine } \\ \text { MeOH: } & \text { Methyl alcohol } \\ \text { MITF: } & \text { Microphthalmia-associated transcription } \\ & \text { factor } \\ \text { NaOH: } & \text { Sodium hydroxide } \\ \text { PTU: } & \text { Phenylthiourea } \\ \text { TRP-1: } & \text { Tyrosinase-related protein-1. }\end{array}$

\section{Conflicts of Interest}

The authors declare no conflicts of interest.

\section{Authors' Contributions}

Soon-Ho Yim and Nadia Tabassum have equal contribution.

\section{Acknowledgments}

This work was supported by the Bio \& Medical Technology Development Program and Basic Science Research Program of the NRF funded by the Korean government, MSIP (NRF2015M3A9C6030838, NRF-2015R1A2A2A11001597, and NRF2016R1A2B4012321). This work was supported by GIST Research Institute (GRI) grant funded by the GIST in 2017.

\section{References}

[1] B. R. McNaughton, P. C. Gareiss, S. E. Jacobs, A. F. Fricke, G. A. Scott, and B. L. Miller, "A potent activator of melanogenesis identified from small-molecule screening," ChemMedChem, vol. 4, no. 10, pp. 1583-1589, 2009.

[2] K. Ezzedine, V. Eleftheriadou, M. Whitton, and N. van Geel, "Vitiligo," The Lancet, vol. 386, no. 9988, pp. 74-84, 2015.

[3] RA. Lewis, Oculocutaneous Albinism Type 1, Seattle, Seattle, WA, USA, 1993.

[4] D. A. Brown, "Skin pigmentation enhancers," Journal of Photochemistry and Photobiology B: Biology, vol. 63, no. 1-3, pp. 148161, 2001.

[5] J.-P. Perchellet and R. K. Boutweu, "Comparison of the effects of 3-isobutyl-1-methylxanthine and adenosine cyclic $3^{\prime}: 5^{\prime}$ monophosp -hate on the induction of skin tumors by the initiation-promotion protocol and by the complete carcinogenesis process," Carcinogenesis, vol. 3, no. 1, pp. 53-60, 1982.

[6] L. A. Hansen, N. A. Monteiro-Riviere, and R. C. Smart, "Differential down-regulation of epidermal protein kinase $\mathrm{C}$ by $12-\mathrm{O}$-tetradecanoylphorbol-13-acetate and diacylglycerol: association with epidermal hyperplasia and tumor promotion," Cancer Research, vol. 50, no. 18, pp. 5740-5745, 1990.

[7] S. Kordali, A. Cakir, A. Mavi, H. Kilic, and A. Yildirim, "Screening of chemical composition and antifungal and antioxidant activities of the essential oils from three Turkish Artemisia species," Journal of Agricultural and Food Chemistry, vol. 53, no. 5, pp. 1408-1416, 2005.

[8] T.-S. Wu, Z.-J. Tsang, P.-L. Wu et al., "New constituents and antiplatelet aggregation and anti-HIV principles of Artemisia capillaris," Bioorganic \& Medicinal Chemistry, vol. 9, no. 1, pp. 77-83, 2001.

[9] C.-Y. Chu, T.-H. Tseng, J.-M. Hwang, F.-P. Chou, and C.-J. Wang, "Protective effects of capillarisin on tert-butylhydroperoxide-induced oxidative damage in rat primary hepatocytes," Archives of Toxicology, vol. 73, no. 4-5, pp. 263-268, 1999. 
[10] I. J. Seon, Y.-J. Kim, W.-Y. Lee et al., "Scoparone from Artemisia capillaris inhibits the release of inflammatory mediators in RAW 264.7 cells upon stimulation cells by interferon- $\gamma$ plus LPS," Archives of Pharmacal Research, vol. 28, no. 2, pp. 203208, 2005.

[11] J.-H. Hong, J.-W. Lee, J.-H. Park, and I.-S. Lee, "Antioxidative and cytoprotective effects of Artemisia capillaris fractions," BioFactors, vol. 31, no. 1, pp. 43-53, 2007.

[12] Y. Q. Hu, R. X. Tan, M. Y. Chu, and J. Zhou, "Apoptosis in human hepatoma cell line SMMC-7721 induced by watersoluble macromolecular components of Artemisia capillaris Thunberg," Japanese Journal of Cancer Research, vol. 91, no. 1, pp. 113-117, 2000.

[13] N. Lv, J. H. Koo, H. Y. Yoon et al., "Effect of angelica gigas extract on melanogenesis in B16 melanoma cells," International Journal of Molecualr Medicine, vol. 20, no. 5, pp. 763-767, 2007.

[14] J.-H. Koo, T. K. Hyoung, H.-Y. Yoon et al., "Effect of xanthohumol on melanogenesis in B16 melanoma cells," Experimental and Molecular Medicine, vol. 40, no. 3, pp. 313-319, 2008.

[15] J. H. Kim, E. J. Baek, E. J. Lee et al., "Ginsenoside F1 attenuates hyperpigmentation in B16F10 melanoma cells by inducing dendrite retraction and activating Rho signalling," Experimental Dermatology, vol. 24, no. 2, pp. 150-152, 2015.

[16] R. A. Sturm, N. F. Box, and M. Ramsay, "Human pigmentation genetics: the difference is only skin deep," BioEssays, vol. 20, no. 9, pp. 712-721, 1998.

[17] X. Zhang, X. Hu, A. Hou, and H. Wang, "Inhibitory effect of 2,4,2',4'-tetrahydroxy-3-(3-methyl-2-butenyl)-chalcone on tyrosinase activity and melanin biosynthesis," Biological and Pharmaceutical Bulletin, vol. 32, no. 1, pp. 86-90, 2009.

[18] T. Mosmann, "Rapid colorimetric assay for cellular growth and survival: application to proliferation and cytotoxicity assays," Journal of Immunological Methods, vol. 65, no. 1-2, pp. 55-63, 1983.

[19] C. Harper and C. Lawrence, The Laboratory Zebrafish (Laboratory Animal Pocket Reference), CRC Press, 2012.

[20] Y.-J. Chen, M.-S. Shiao, M.-L. Hsu, T.-H. Tsai, and S.-Y. Wang, "Effect of caffeic acid phenethyl ester, an antioxidant from propolis, on inducing apoptosis in human leukemic HL-60 cells," Journal of Agricultural and Food Chemistry, vol. 49, no. 11, pp. 5615-5619, 2001.

[21] T.-Y. Choi, J.-H. Kim, D. H. Ko et al., "Zebrafish as a new model for phenotype-based screening of melanogenic regulatory compounds," Pigment Cell Research, vol. 20, no. 2, pp. 120-127, 2007.

[22] D. J. Milan, T. A. Peterson, J. N. Ruskin, R. T. Peterson, and C. A. MacRae, "Drugs that induce repolarization abnormalities cause bradycardia in zebrafish," Circulation, vol. 107, no. 10, pp. 13551358, 2003.

[23] J. Richardson, P. R. Lundegaard, N. L. Reynolds et al., "mclr pathway regulation of zebrafish melanosome dispersion," Zebrafish, vol. 5, no. 4, pp. 289-295, 2008.

[24] N. Tabassum, J.-H. Lee, S.-H. Yim, G. J. Batkhuu, D.-W. Jung, and D. R. Williams, "Isolation of 4,5-O-dicaffeoylquinic acid as a pigmentation inhibitor occurring in artemisia capillaris thunberg and its validation in vivo," Evidence-Based Complementary and Alternative Medicine, vol. 2016, Article ID 7823541, 11 pages, 2016.

[25] M. Nazzaro-Porro, G. Zina, A. Breathnach et al., "Effect of azelaic acid on human malignant melanoma," The Lancet, vol. 315, no. 8178, pp. 1109-1111, 1980.
[26] J. Vachtenheim and J. Borovanský, “'Transcription physiology' of pigment formation in melanocytes: central role of MITF," Experimental Dermatology, vol. 19, no. 7, pp. 617-627, 2010.

[27] C. A. Ferguson and S. H. Kidson, "The regulation of tyrosinase gene transcription," Pigment Cell Research, vol. 10, no. 3, pp. 127138, 1997.

[28] D.-W. Jung, D. Williams, S. M. Khersonsky et al., "Identification of the F1F0 mitochondrial ATPase as a target for modulating skin pigmentation by screening a tagged triazine library in zebrafish," Molecular BioSystems, vol. 1, no. 1, pp. 85-92, 2005.

[29] A. Poma, S. Bianchini, and M. Miranda, "Inhibition of Ltyrosine-induced micronuclei production by phenylthiourea in human melanoma cells," Mutation Research, vol. 446, no. 2, pp. 143-148, 1999.

[30] D. Y. R. Stainier, B. Fouquet, J. N. Chen et al., "Mutations affecting the formation and function of the cardiovascular system in the zebrafish embryo," Development, vol. 123, pp. 285292, 1996.

[31] S. Colanesi, K. L. Taylor, N. D. Temperley et al., "Small molecule screening identifies targetable zebrafish pigmentation pathways," Pigment Cell and Melanoma Research, vol. 25, no. 2, pp. 131-143, 2012. 


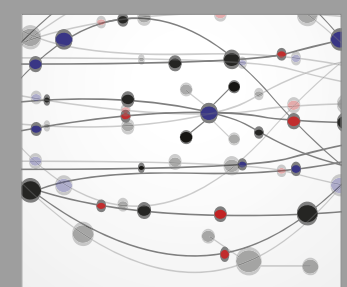

The Scientific World Journal
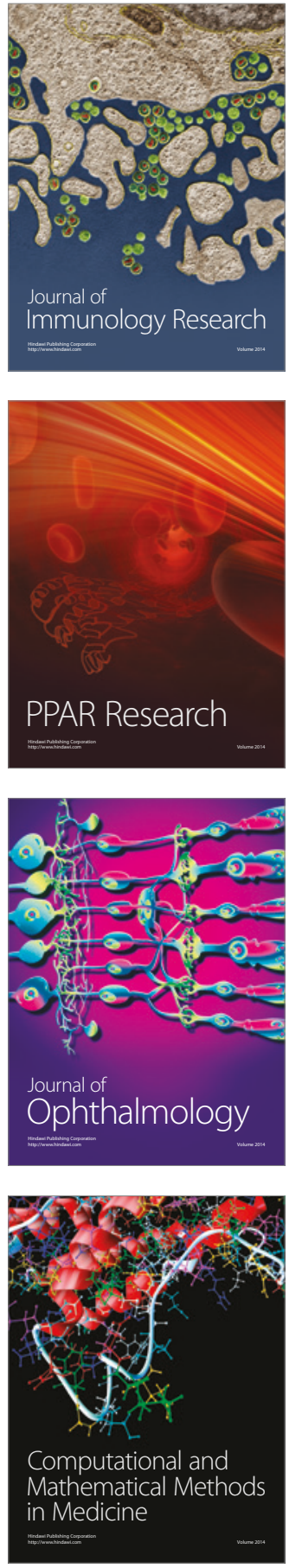

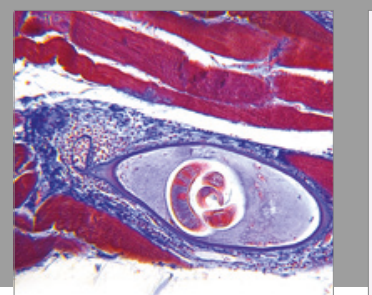

Gastroenterology Research and Practice
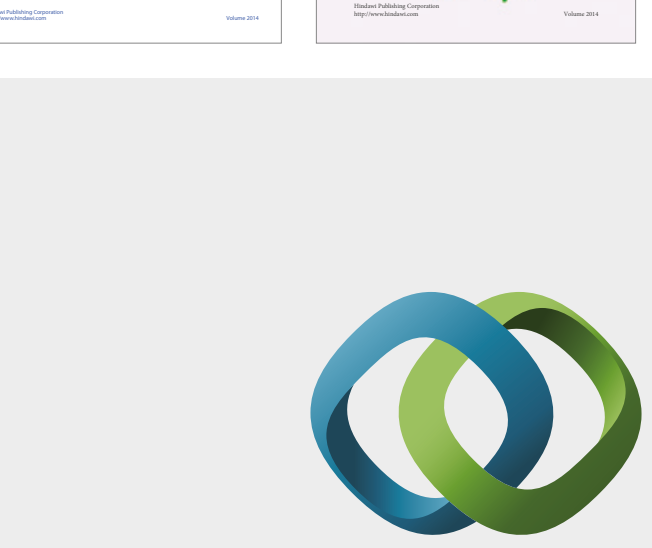

\section{Hindawi}

Submit your manuscripts at

https://www.hindawi.com
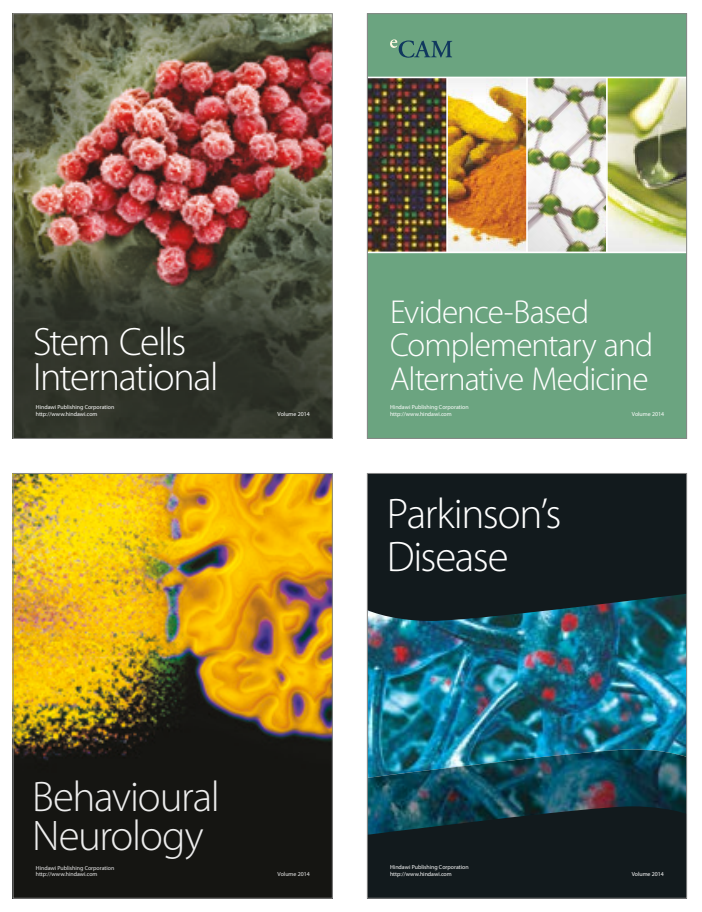
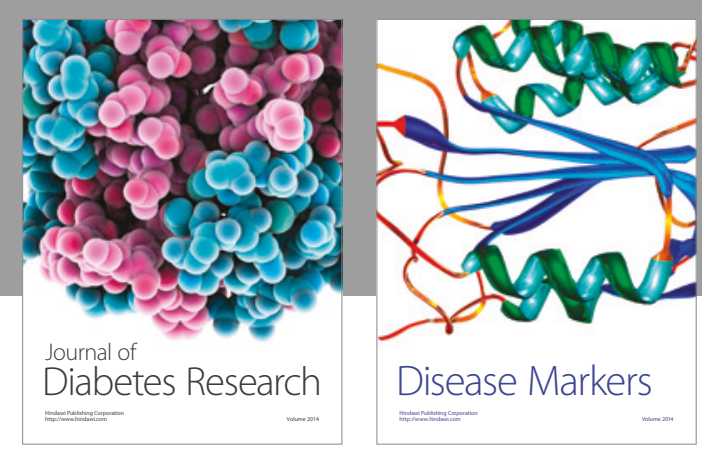

Disease Markers
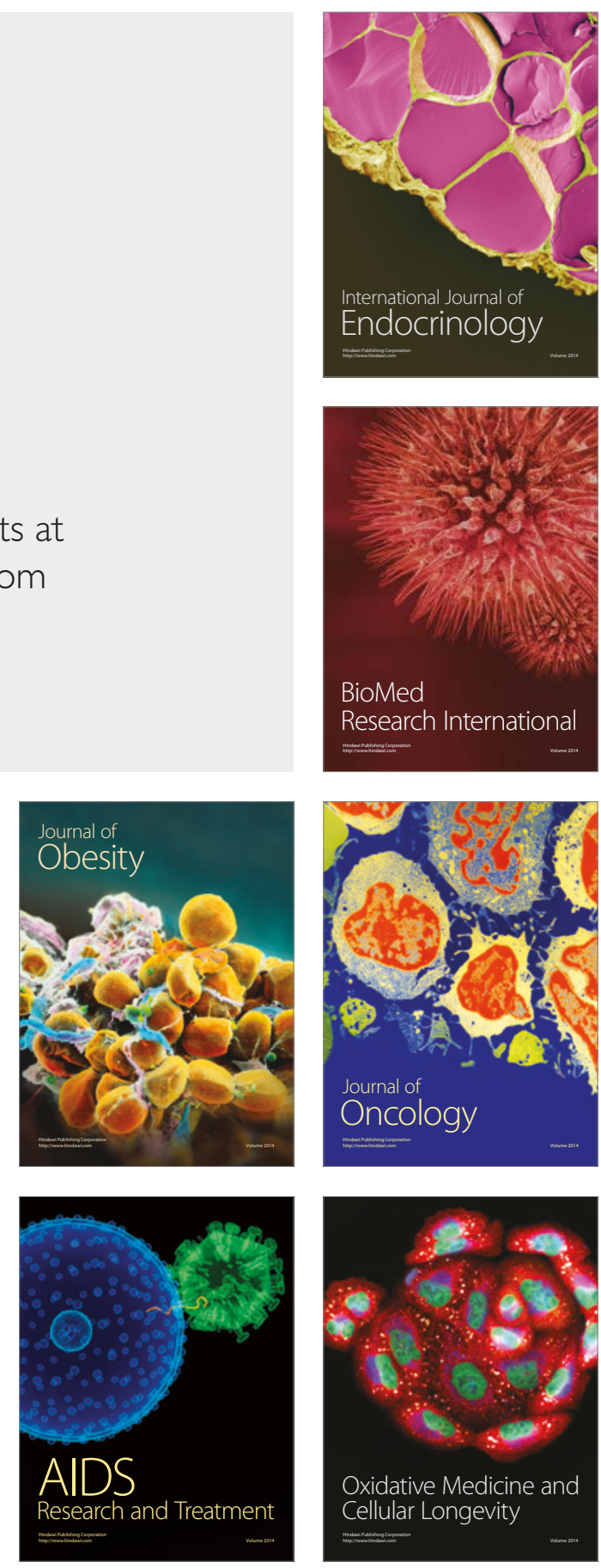